\title{
Physical properties of unproductive soils of Northern China**
}

\author{
Zaffar Malik, Muhammad Akbar Malik, Zong Yu-Tong ${ }^{1}$, and Lu Sheng-Gao ${ }^{1 *}$ \\ ${ }^{1}$ Zhejiang Provincial Key Laboratory of Subtropical Soil and Plant Nutrition, Ministry of Education \\ Key Laboratory of Environmental Remediation and Ecosystem Health, College of Environmental and Resource Sciences, \\ Zhejiang University, Hangzhou 310058, P. R. China \\ ${ }^{2}$ Department of Civil Engineering and Architecture, Zhejiang University, Hangzhou 310058, P. R. China
}

Received November 11, 2013; accepted September 18, 2014

\begin{abstract}
A b s t r a c t. The general characteristics: particle size distribution, $\mathrm{pH}$, cation exchange capacity, organic matter content, total NPK, surface area; and physical properties: coefficient of linear extensibility, tensile strength, shear strength and cracking, were investigated in unproductive soils of Northern China. Principle component analysis showed that tensile strength, cohesion, cracking characteristics, clay content, cation exchange capacity and coefficient of linear extensibility were positively correlated with each other, whereas negatively correlated with angle of friction, indicating that these properties were subjected to clay $\%$ and smectite content. These correlations might be mainly responsible for low productivity (low yields) in Northern China.

K e y w o r d: unproductive soils, physical properties, Northern China
\end{abstract}

\section{INTRODUCTION}

The unproductive (low yield) soils in China are distributed in many climatic zones (tropical, subtropical and temperate zones) in general, and in semi-arid regions of Northern China particularly (Li et al., 2011; Liangwu, 1991). These soilswere formedunderdiversesoilforming conditions which include alternative wet and dry climate, low and flat topography, heavy texture, and parent material with high bases concentrations. These soils are also formed locally due to special parent material, heavy deposition of basalt and carbonates, and clay textured material from rivers and lakes (Xuelei and Zitong, 2004). Shrinkage and swelling of clay dominated by montmorillionite undergoing periods of drying and wetting is another factor contributing to their formation (Min et al., 1993). Limestone, basalt or other calcium and magnesium rich parent material formed

*Corresponding author e-mail: lusg@zju.edu.cn

**This work was supported by the National Key Basic Research Support Foundation of China (973) (2011CB100502) 2010-2015. swelling type clays, which made them unproductive soils. Besides this, there are some other properties which also make them difficult for management, including cracking, soil strength properties, specific volume, aggregate stability, soil shrinkage characteristics and plasticity index. The unproductive Northern China soils are also famous for their improper structure and low yield caused by faulty physical properties, high amount of clay contents, cation exchange capacity (CEC) and smectite mineral (Li et al., 2011). Generally, clay mineral defines the size, shape and surface characteristics, and thereby determines the engineering properties of soil.

Soil physical properties largely affect the soil functions, including nutrients uptake, water movement, microbial activities etc., and their management. Clay particles $(<0.002 \mathrm{~mm})$, due to their large surface area and mineral composition, control many physical properties like shrinkswell behaviour, plasticity, soil strength and chemical adsorption. Mechanical properties of soil like coefficient of linear extensibility (COLE), tensile strength and shear strength play an important role for slope stability, seedling emergence, root growth and plant development. Previously, the effect of mineralogy and clay content on the mechanical properties has been widely recognized and publicised (Greene et al., 2002). A relationship between smectite and COLE described that smectite and clay content increased the COLE values and shrink and swell potential (Moustakas, 1990). Similarly, tensile strength of Na-saturated remoulded core was highly correlated with clay $\%$ and CEC (Greene et al., 2002). In another study, shear strength of soil was found to be subject to clay mineralogy and amount of soil constituents (Tiwari and Marui, 2003). The size, rate and

(C) 2014 Institute of Agrophysics, Polish Academy of Sciences 
frequency of cracks are responsible for water and air movement, leaching of nutrients and emission of gases, and thus influence soil productivity and causes ground water pollution (Bandyopadhyay et al., 2003; Dadfar et al., 2010). In addition, the swelling and shrinkage phenomenon proved to dynamically change soil porosity and pore size distribution and deteriorate the soil structure. The unproductive soils of Northern China are also significant soil resources for the country and have been cultivated for thousands of years. Thus it is important to characterise these soils from the physical and mineralogical point of view for sustainable crop production and to adopt better soil management practices.

Therefore this study was conducted with the objectives to examine the mineralogical characteristics, to determine the particle size distribution (PSD), other properties such as COLE, tensile strength, and shear strength, and cracking parameters, and to establish the relationships of these parameters with other soil properties.

\section{MATERIALS AND METHODS}

Six soil profile samples were collected from typical 'low yield soils' (locally called Shajiang Black Soils) of Northern China. The sampling sites are located in Anhui

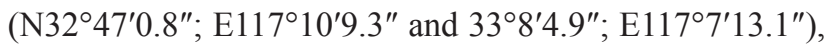

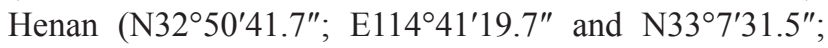

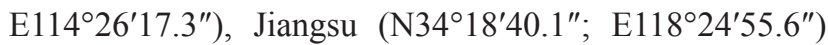
and Shandong (N34 $35^{\prime} 45.5^{\prime \prime}$; E118 $\left.18^{\circ} 19.3^{\prime \prime}\right)$ provinces of Northern China (Fig. 1). They were crushed and passed through $2 \mathrm{~mm}$ mesh and stored for further use. Soil profiles were labelled (Anhui soils $=\mathrm{AH}-05$ and $\mathrm{AH}-09$; Shandong soil $=$ SD-01; Henan soils $=\mathrm{HN}-03$ and HN-10 and Jiangsu soil $=$ JS-07). These soils were classified as the Typical Calci-Aquic Vertisols (AH-05, 09, HN-03, 10) and Shajiang-Aquic Camosols (SD-01 and JS-07) according to Chinese Soil Taxonomy (Li et al., 2011).

Stones, gravels and plant debris were removed and then samples were air dried. The basic properties of soil are listed in Table 1. Analyses of soil chemical and physical properties were carried out according to routine procedures (Bao, 2000). The particle size distribution (PSD) was determined by a combination of wet sieving and pipette methods. Soil $\mathrm{pH}$ was determined using a 1:2.5 soil to water ratio with a $\mathrm{pH}$ meter, $\mathrm{OM}$ was determined by dichromate oxidation method, and CEC was measured by $\mathrm{NH}_{4}$ acetate method. Total $\mathrm{N}$ was measured with a Rapid N Cube Nitrogen Analyser. Total $\mathrm{P}$ was determined colorimetrically as ammonium molybdate-ascorbic acid, following $\mathrm{H}_{2} \mathrm{SO}_{4}-$ $\mathrm{HClO}_{4}$ digestion, whereas total $\mathrm{K}$ was analyzed by atomic absorption spectrophotometer after three acid digestion. The clay fraction $(<2 \mu \mathrm{m})$ was separated using sedimentary method after organic matter and carbonate were removed. The clay fraction was further saturated with $\mathrm{K}, \mathrm{Mg}$ and glycolated with ethylene glycerol for XRD analysis.

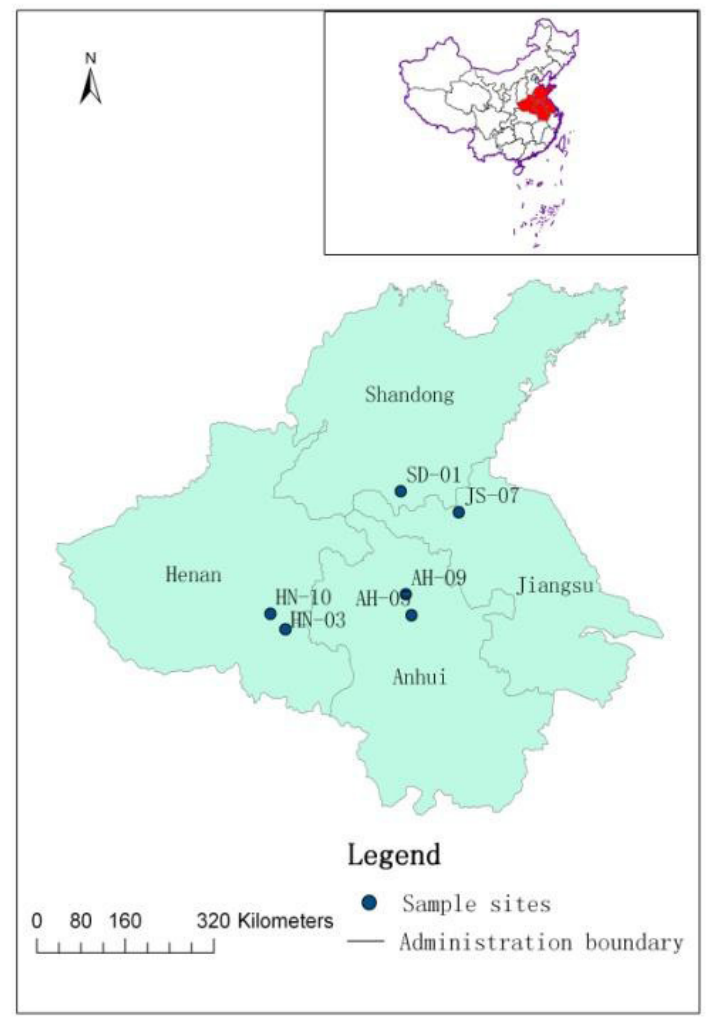

Fig. 1. Schematic map of sampling sites in northern part of China.

Samples were saturated with $0.5 \mathrm{M} \mathrm{Mg} \mathrm{Cl}_{2} 6 \mathrm{H}_{2} \mathrm{O}$ and $1 \mathrm{M} \mathrm{KCl}$ solutions whereas glycolation was achieved by exposing the clay samples to ethylene glycol vapours in desiccators in an oven at $60^{\circ} \mathrm{C}$ for $6 \mathrm{~h}$. K saturated samples were further heated at 330 and $550^{\circ} \mathrm{C}$ to clearly distinguish mixed layer expandable 2:1 clay minerals in the samples. The XRD patterns were recorded (Rigaku d/Max 2550pc) at $\mathrm{Cu} \mathrm{K} \alpha$ radiation at $40 \mathrm{KV}$ and $45 \mathrm{~mA}$. The samples were scanned from 3 to $40^{\circ} 2 \theta$ with step width of $0.02 \theta^{\circ}$. All the mineral phases were identified by JADE 6.5 and were drawn in Origin 8 software.

The coefficient of linear extensibility (COLE) of soils was measured on ground remoulded samples by following the method of Schafer and Singer (1976). For this purpose air-dried soil of $100 \mathrm{~g}(<2 \mathrm{~mm})$ was used to make paste slightly drier than saturation and kept for $24 \mathrm{~h}$ to achieve equilibrium. The paste was loaded into a syringe and rods of varying length $(5-10 \mathrm{~cm})$ were extruded on glass plate. The resulting rods were trimmed from both sides and their length was measured. The rods were air dried and their length was measured again to calculate COLE by the following formula:

$$
\operatorname{COLE}=\left(\mathrm{L}_{\mathrm{m}}-\mathrm{L}_{\mathrm{d}}\right) / \mathrm{L}_{\mathrm{d}},
$$

where: $\mathrm{L}_{\mathrm{m}}$ and $\mathrm{L}_{\mathrm{d}}$ are the length of dry and moist soils, respectively. Tensile strength of soils was measured by crushing method. Remoulded soil cores $(2 \mathrm{~cm}$ in diameter and 
T a b l e 1. Basic soil properties of studied soils

\begin{tabular}{|c|c|c|c|c|c|c|c|c|c|c|c|c|}
\hline \multirow[b]{2}{*}{ Profile } & \multirow{2}{*}{$\begin{array}{l}\text { Depth } \\
(\mathrm{cm})\end{array}$} & \multirow[b]{2}{*}{$\mathrm{pH}$} & \multirow{2}{*}{$\begin{array}{c}\mathrm{CEC} \\
\left(\mathrm{Cmol} \mathrm{kg}^{-1}\right)\end{array}$} & \multirow{2}{*}{$\begin{array}{c}\mathrm{OM} \\
\left(\mathrm{g} \mathrm{kg}^{-1}\right)\end{array}$} & \multicolumn{3}{|c|}{ Total $\left(\mathrm{g} \mathrm{kg}^{-1}\right)$} & \multicolumn{5}{|c|}{ Particle size distribution $(\mathrm{mm})(\%)$} \\
\hline & & & & & $\mathrm{N}$ & $\mathrm{P}$ & $\mathrm{K}$ & $>0.25$ & $\begin{array}{c}0.25- \\
0.05\end{array}$ & $\begin{array}{c}0.05- \\
0.02\end{array}$ & $\begin{array}{l}0.02- \\
0.002\end{array}$ & $<0.002$ \\
\hline \multirow{5}{*}{ AH-05 } & $0-20$ & 6 & 50.72 & 15.68 & 1.21 & 1.13 & 0.52 & 0.47 & 0.45 & 18.07 & 50.97 & 30.03 \\
\hline & $20-50$ & 6.32 & 54.45 & 12.29 & 0.85 & 1.06 & 0.51 & 0.86 & 2.32 & 9.55 & 47.59 & 39.67 \\
\hline & $50-70$ & 7.3 & 58.48 & 3.9 & 0.72 & 1.27 & 0.45 & 2.14 & 8.10 & 14.21 & 38.03 & 37.52 \\
\hline & $70-90$ & 7.55 & 57.36 & 5.02 & 0.83 & 1.65 & 0.42 & 1.63 & 6.01 & 7.44 & 43.93 & 40.99 \\
\hline & $0-20$ & 5.62 & 46.54 & 13.13 & 0.51 & 3.93 & 0.61 & 0.96 & 1.22 & 29.07 & 36.67 & 32.08 \\
\hline \multirow{3}{*}{ AH-09 } & $20-40$ & 6.8 & 46.55 & 8.37 & 0.34 & 3.21 & 0.55 & 0.46 & 2.06 & 26.54 & 34.18 & 36.76 \\
\hline & $40-60$ & 7.36 & 43.42 & 7.87 & 0.41 & 2.7 & 0.43 & 1.12 & 1.21 & 14.07 & 51.72 & 31.88 \\
\hline & $>60$ & 7.31 & 51.32 & 1.89 & 0.38 & 2.22 & 0.43 & 0.77 & 0.93 & 20.16 & 37.02 & 41.12 \\
\hline \multirow{6}{*}{ SD-01 } & $0-16$ & 6.65 & 41.70 & 10.41 & 0.9 & 1.47 & 1.12 & 12.25 & 23.08 & 10.05 & 29.19 & 25.43 \\
\hline & $16-25$ & 6.84 & 42.22 & 5.59 & 0.73 & 1.36 & 0.97 & 11.93 & 20.23 & 14.26 & 30.64 & 22.95 \\
\hline & $25-37$ & 7.3 & 43.27 & 3.91 & 0.74 & 1.34 & 0.78 & 11.24 & 22.25 & 13.13 & 35.19 & 18.19 \\
\hline & $37-60$ & 7.49 & 47.89 & 1.36 & 0.6 & 0.94 & 0.73 & 6.99 & 18.14 & 12.51 & 37.03 & 25.33 \\
\hline & $60-80$ & 7.48 & 47.52 & 1.47 & 0.39 & 0.72 & 0.65 & 6.71 & 15.63 & 15.08 & 34.68 & 27.91 \\
\hline & $>80$ & 7.33 & 15.53 & 1.82 & 0.42 & 0.89 & 0.63 & 12.25 & 23.08 & 10.05 & 29.19 & 25.43 \\
\hline \multirow{5}{*}{$\mathrm{HN}-03$} & $0-20$ & 6.2 & 43.57 & 11.42 & 0.8 & 1.46 & 1.23 & 0.42 & 0.39 & 14.75 & 59.21 & 25.24 \\
\hline & $20-50$ & 6.43 & 59.60 & 10.14 & 0.79 & 1.51 & 0.89 & 1.42 & 2.76 & 16.04 & 44.51 & 35.27 \\
\hline & $50-100$ & 6.61 & 41.33 & 6.73 & 0.58 & 1.25 & 0.74 & 0.34 & 0.63 & 19.55 & 49.05 & 30.44 \\
\hline & $\begin{array}{c}100- \\
170\end{array}$ & 6.81 & 45.28 & 2.75 & 0.47 & 0.85 & 0.74 & 0.42 & 1.26 & 28.24 & 38.69 & 31.40 \\
\hline & $>170$ & 7.23 & 45.80 & 4.97 & 0.42 & 0.89 & 0.73 & 0.38 & 1.19 & 30.49 & 38.31 & 29.63 \\
\hline \multirow{5}{*}{$\mathrm{HN}-10$} & $0-35$ & 6.23 & 41.85 & 12.97 & 1.4 & 1.91 & 0.97 & 0.46 & 1.22 & 25.49 & 43.87 & 28.96 \\
\hline & $35-60$ & 6.08 & 48.79 & 8.3 & 1.41 & 1.7 & 0.82 & 0.34 & 0.70 & 17.11 & 46.93 & 34.92 \\
\hline & $60-100$ & 7.24 & 50.35 & 7.19 & 0.88 & 1.34 & 0.68 & 0.19 & 0.29 & 26.28 & 32.96 & 40.28 \\
\hline & $\begin{array}{c}100- \\
150\end{array}$ & 7.32 & 39.99 & 2.74 & 0.70 & 1.15 & 0.65 & 0.49 & 2.24 & 30.36 & 39.83 & 27.08 \\
\hline & $>150$ & 7.26 & 39.46 & 2.47 & 0.73 & 0.7 & 0.63 & 0.87 & 3.63 & 38.31 & 29.92 & 27.27 \\
\hline \multirow{5}{*}{ JS-07 } & $0-20$ & 6.9 & 32.83 & 15.83 & 0.84 & 2.25 & 0.67 & 27.70 & 11.62 & 17.32 & 26.65 & 16.72 \\
\hline & $20-40$ & 7 & 38.72 & 25.3 & 0.82 & 1.19 & 0.64 & 30.48 & 12.65 & 20.79 & 19.05 & 17.04 \\
\hline & $40-60$ & 7.29 & 42.82 & 4.93 & 0.79 & 0.96 & 0.53 & 28.13 & 22.03 & 16.35 & 15.97 & 17.52 \\
\hline & $60-80$ & 7.38 & 43.86 & 1.62 & 0.63 & 0.89 & 0.37 & 26.24 & 18.72 & 12.17 & 23.79 & 19.08 \\
\hline & $80-100$ & 7.6 & 43.04 & 0.2 & 0.21 & 0.68 & 0.28 & 33.58 & 18.91 & 12.18 & 17.90 & 17.44 \\
\hline
\end{tabular}


$4 \mathrm{~cm}$ in height) were saturated under capillary action for $24 \mathrm{~h}$, equilibrated on pressure plate for $12 \mathrm{~h}$ and air dried at $105^{\circ} \mathrm{C}$ for $2 \mathrm{~h}$. The soil cores were adjusted between two parallel plates of a digital unconfined compression apparatus (YYW-2, Nanjing Soil Instrument Factory Co. Ltd.). Pressure was applied on soil cores through plates by a motor at constant speed of $2 \mathrm{~mm} \mathrm{~min}^{-1}$. The maximum reading was noted prior to core fracture under the pressure.

Direct shear tests (DST) were applied to determine the shear strength of soil profiles by a quadruplex strain controlled direct shear apparatus (Nanjing Soil Instrument Factory Co. Ltd.). Uniform soil cores of $6.18 \mathrm{~cm}$ in diameter and $2 \mathrm{~cm}$ in height were saturated for $24 \mathrm{~h}$. The soil cores were then equilibrated at $300 \mathrm{hPa}$ matric potential for $12 \mathrm{~h}$. The equilibrated cores were mounted on the shear testing device consisting of a soil shear box, a loading head, a weight hanger, and weights of different loads. Loads of $50,100,200$ and $400 \mathrm{kPa}$ were applied to measure the shear strength of clayey soils (Lu et al., 2014). A lateral displacement at a speed of $0.8 \mathrm{~mm} \mathrm{~min}^{-1}$ was applied until failure occurred and the maximum shear force was recorded. The cohesion (c) and the angle of internal friction $(\varphi)$ were obtained by the Mohr-Coulomb theory.

In order to investigate the cracking behaviour of the soils a laboratory experiment was conducted. Uniform soil slurries were made ( $50 \mathrm{~g}$ soil and $28 \mathrm{ml}$ water) and spread on glass plates with size of $10 \times 10 \times 2 \mathrm{~cm}$. The glass plates were put into an oven to develop cracks at $35^{\circ} \mathrm{C}$. Digital images were obtained after the development of cracks with the help of a digital camera. These images were processed in Erdos9.2 software to get binary images and were than digitized in ArcView 9.0 and analysed in arc GIS 9.0 to calculate crack area, length and width (Donghong et al., 2013).

All the parameters in the study were replicated three times. The means were compared by SPSS 1.3 statistical package. Principal component analysis (PCA) based on factor analysis was used to find out correlations among different soil parameters. In PCA factor loadings with varimax rotation were used.

\section{RESULTS}

The unproductive soils of Northern China were characterized for their physical and mechanical properties in order to investigate the reason for their low yield. The PSD values showed that all the profiles contained a high amount of clay $(<0.002 \mathrm{~mm})$, except for profile JS-07 (Table 1). Tensile strength values for profile AH-05 increased at 20-50 $\mathrm{cm}$ and 70-90 $\mathrm{cm}$ depths (Table 2). Profile AH-09 had high values at upper horizon while its tensile strength decreased at lower horizons. Profile SD-01 showed an increase in the values of tensile strength with increasing depth. Profile HN-03 showed a low tensile strength at upper sub-layers while high values were noted at lower layers. In contrast to profile $\mathrm{HN}-03$, in profile $\mathrm{HN}-10$ high values at upper and middle layers were observed. In contrast to other profiles, profile JS-07 had decreasing values of tensile strength with increasing depth.

Table 2 also presents the shear strength of soil profiles along the depth. The shear strength is expressed in cohesion and angle of friction. Profile AH-05 had high values of cohesion from top layers to bottom layers while the angle of friction decreased significantly in a similar pattern. Profile AH-09 showed high cohesion at upper layer while at lower layer, at depth $>60 \mathrm{~cm}$, the value of cohesion decreased significantly and the angle of friction increased from top to bottom compared to profile $\mathrm{AH}-05$. In profile SD-01 cohesion had high values at top layer and then decreased gradually along with depth, and the angle of friction did not show any significant difference with depth except some low values at lower depths. For profile HN-03, low values of cohesion were observed at depths of $0-20 \mathrm{~cm}$ and $>170 \mathrm{~cm}$ and high values were noted at middle layers, while opposite trends for the angle of friction were noted at the same depths. A little increase in the values of cohesion was observed for profile $\mathrm{HN}-10$ at middle layer, but low cohesion was found at top and bottom depths. However, the values for the angle of friction showed similar trends as was observed in profile HN-03. Profile JS-07 showed high values of cohesion at lower layers $(80-100 \mathrm{~cm})$ while no marked difference was observed for other layers, whereas the values for the angle of friction decreased with depth.

Table 3 represents the crack area, length and width. It is clear that the crack surface area increased with depth in profiles $\mathrm{AH}-05, \mathrm{AH}-09$ and SD-01. In profile $\mathrm{AH}-05$ crack length and width increased with increasing depth except for depth $50-70 \mathrm{~cm}$ where a small decrease in crack length was found. Crack length in profile AH-09 decreased from top layer to bottom layer, whereas crack width increased in a similar fashion. Profile SD-01 showed no prominent differences in crack length at upper layer while crack length increased at lower layers, whereas crack width decreased at lower depths. Cracking parameters (area, length and width) of profile HN-03 decreased with increasing depths except for crack length value at depth of $100-170 \mathrm{~cm}$. Similar trends were observed for profile $\mathrm{HN}-10$ where crack parameters decreased along with depth, except at depth 35-60 $\mathrm{cm}$ which showed high values for crack area, length and width. The values of crack area and length increased with increasing depth in profile JS-07, while the increase in crack length was more pronounced. In contrast to crack area and length, crack width decreased with the depth (Table 3) in profile JS-07.

Figure 2 presents the variation in the COLE values of all soil profiles with the depth. The COLE values ranged from 0.02 to 0.13 in all profiles. The COLE values increased with depth in all profiles except for some low values at lower depth, $>80$ and $>150 \mathrm{~cm}$, for profiles SD-07 and $\mathrm{HN}-10$, respectively. XRD analysis of six soil profiles of Northern China for mineral phase identification is shown in Figs 3, 4. Figure 3 includes air dried samples of all profiles 
T a b l e 2. Physical properties of studied soils

\begin{tabular}{|c|c|c|c|c|}
\hline \multirow{2}{*}{ Profile } & \multirow{2}{*}{$\begin{array}{c}\text { Depth } \\
(\mathrm{cm})\end{array}$} & \multirow{2}{*}{ Tensile strength $(\mathrm{kPa})$} & \multicolumn{2}{|c|}{ Shear strength } \\
\hline & & & $\mathrm{C}(\mathrm{kPa})$ & $\varphi\left({ }^{\circ}\right)$ \\
\hline \multirow{4}{*}{ AH-05 } & $0-20$ & $5433.47 \pm 78.10$ & $22.42 \pm 0.53$ & $18.24 \pm 0.30$ \\
\hline & $20-50$ & $6466.85 \pm 150.03$ & $33.32 \pm 0.48$ & $6.34 \pm 0.15$ \\
\hline & $50-70$ & $5151.87 \pm 158.41$ & $29.29 \pm 0.27$ & $1.30 \pm 0.11$ \\
\hline & $70-90$ & $9177.42 \pm 32.05$ & $27.88 \pm 0.23$ & $3.23 \pm 0.08$ \\
\hline \multirow{4}{*}{ AH-09 } & $0-20$ & $8757.02 \pm 47.69$ & $29.90 \pm 0.23$ & $9.73 \pm 0.08$ \\
\hline & $20-40$ & $9695.64 \pm 94.10$ & $23.04 \pm 0.14$ & $12.45 \pm 0.10$ \\
\hline & $40-60$ & $6469.79 \pm 105.81$ & $28.57 \pm 0.52$ & $13.36 \pm 0.17$ \\
\hline & $>60$ & $6840.76 \pm 68.67$ & $10.38 \pm 0.18$ & $15.76 \pm 0.19$ \\
\hline \multirow{6}{*}{ SD-01 } & $0-16$ & $1074.47 \pm 57.33$ & $25.93 \pm 0.56$ & $20.02 \pm 0.19$ \\
\hline & $16-25$ & $2942.32 \pm 46.74$ & $30.58 \pm 0.32$ & $22.48 \pm 0.37$ \\
\hline & $25-37$ & $2082.91 \pm 50.79$ & $27.95 \pm 0.06$ & $21.53 \pm 0.33$ \\
\hline & $37-60$ & $2396.79 \pm 18.72$ & $26.57 \pm 0.28$ & $22.53 \pm 0.22$ \\
\hline & $60-80$ & $2466.94 \pm 42.26$ & $21.44 \pm 0.37$ & $17.55 \pm 0.30$ \\
\hline & $>80$ & $3277.78 \pm 31.63$ & $18.44 \pm 0.45$ & $17.67 \pm 0.38$ \\
\hline \multirow{5}{*}{$\mathrm{HN}-03$} & $0-20$ & $4260.99 \pm 51.24$ & $13.65 \pm 0.32$ & $22.83 \pm 0.35$ \\
\hline & $20-50$ & $5569.04 \pm 48.13$ & $26.67 \pm 0.28$ & $9.37 \pm 0.17$ \\
\hline & $50-100$ & $6931.62 \pm 43.31$ & $21.65 \pm 0.43$ & $12.36 \pm 0.13$ \\
\hline & $100-170$ & $7944.54 \pm 67.37$ & $18.01 \pm 0.18$ & $18.54 \pm 0.27$ \\
\hline & $>170$ & $7734.33 \pm 47.36$ & $13.53 \pm 0.35$ & $15.43 \pm 0.18$ \\
\hline \multirow{5}{*}{$\mathrm{HN}-10$} & $0-35$ & $7768.09 \pm 52.19$ & $12.11 \pm 0.13$ & $20.59 \pm 0.19$ \\
\hline & $35-60$ & $5670.32 \pm 53.50$ & $18.70 \pm 0.35$ & $11.63 \pm 0.33$ \\
\hline & $60-100$ & $10114.39 \pm 63.78$ & $14.89 \pm 0.59$ & $15.54 \pm 0.26$ \\
\hline & $100-150$ & $5393.42 \pm 33.65$ & $24.64 \pm 0.45$ & $10.41 \pm 0.25$ \\
\hline & $>150$ & $5870.78 \pm 39.68$ & $12.57 \pm 0.09$ & $20.25 \pm 0.07$ \\
\hline \multirow{5}{*}{ JS-07 } & $0-20$ & $2347.92 \pm 51.40$ & $19.49 \pm 0.43$ & $26.86 \pm 0.36$ \\
\hline & $20-40$ & $2173.59 \pm 46.27$ & $23.56 \pm 0.26$ & $18.46 \pm 0.63$ \\
\hline & $40-60$ & $1975.15 \pm 61.88$ & $21.66 \pm 0.37$ & $17.82 \pm 0.31$ \\
\hline & $60-80$ & $1065.86 \pm 44.90$ & $19.70 \pm 0.24$ & $20.37 \pm 0.33$ \\
\hline & $80-100$ & $2074.85 \pm 46.87$ & $29.97 \pm 0.35$ & $19.83 \pm 0.39$ \\
\hline
\end{tabular}


T a b l e 3. Cracking parameters of studied soils

\begin{tabular}{|c|c|c|c|c|}
\hline Profile & $\begin{array}{l}\text { Depth } \\
(\mathrm{cm})\end{array}$ & Area $(\%)$ & Length $\left(\mathrm{m} \mathrm{m}^{-2}\right)$ & Width $(\mathrm{cm})$ \\
\hline \multirow{4}{*}{ AH-05 } & $0-20$ & $17.00 \pm 0.20$ & $179.47 \pm 36.52$ & $0.10 \pm 0.02$ \\
\hline & $20-50$ & $26.51 \pm 0.48$ & $230.40 \pm 21.71$ & $0.12 \pm 0.01$ \\
\hline & $50-70$ & $24.54 \pm 0.52$ & $176.73 \pm 17.97$ & $0.14 \pm 0.02$ \\
\hline & $70-90$ & $25.51 \pm 0.24$ & $226.28 \pm 17.06$ & $0.11 \pm 0.01$ \\
\hline \multirow{4}{*}{ AH-09 } & $0-20$ & $18.47 \pm 0.34$ & $243.08 \pm 45.22$ & $0.08 \pm 0.01$ \\
\hline & $20-40$ & $19.32 \pm 0.21$ & $228.99 \pm 30.61$ & $0.09 \pm 0.01$ \\
\hline & $40-60$ & $19.04 \pm 0.30$ & $187.26 \pm 28.45$ & $0.10 \pm 0.02$ \\
\hline & $>60$ & $24.39 \pm 0.27$ & $225.97 \pm 28.56$ & $0.11 \pm 0.01$ \\
\hline \multirow{6}{*}{ SD-01 } & $0-16$ & $13.52 \pm 0.28$ & $149.23 \pm 39.37$ & $0.10 \pm 0.03$ \\
\hline & $16-25$ & $13.63 \pm 0.31$ & $141.56 \pm 33.44$ & $0.10 \pm 0.03$ \\
\hline & $25-37$ & $15.13 \pm 0.60$ & $174.92 \pm 27.45$ & $0.09 \pm 0.01$ \\
\hline & $37-60$ & $17.27 \pm 0.31$ & $172.09 \pm 17.25$ & $0.10 \pm 0.01$ \\
\hline & $60-80$ & $16.40 \pm 0.22$ & $274.47 \pm 25.32$ & $0.06 \pm 0.00$ \\
\hline & $>80$ & $13.60 \pm 0.31$ & $168.44 \pm 31.78$ & $0.08 \pm 0.02$ \\
\hline \multirow{5}{*}{$\mathrm{HN}-03$} & $0-20$ & $22.48 \pm 0.27$ & $197.70 \pm 20.76$ & $0.11 \pm 0.01$ \\
\hline & $20-50$ & $17.72 \pm 0.32$ & $191.43 \pm 34.62$ & $0.09 \pm 0.02$ \\
\hline & $50-100$ & $16.35 \pm 0.39$ & $185.01 \pm 28.85$ & $0.09 \pm 0.02$ \\
\hline & $100-170$ & $16.69 \pm 0.20$ & $203.37 \pm 23.52$ & $0.08 \pm 0.01$ \\
\hline & $>170$ & $15.56 \pm 0.30$ & $183.22 \pm 28.16$ & $0.09 \pm 0.01$ \\
\hline \multirow{5}{*}{$\mathrm{HN}-10$} & $0-35$ & $18.55 \pm 0.37$ & $208.80 \pm 10.06$ & $0.09 \pm 0.00$ \\
\hline & $35-60$ & $21.72 \pm 0.23$ & $224.53 \pm 39.14$ & $0.10 \pm 0.02$ \\
\hline & $60-100$ & $14.34 \pm 0.13$ & $178.82 \pm 23.73$ & $0.08 \pm 0.01$ \\
\hline & $100-150$ & $13.47 \pm 0.30$ & $169.60 \pm 27.41$ & $0.08 \pm 0.01$ \\
\hline & $>150$ & $13.73 \pm 0.29$ & $148.11 \pm 30.92$ & $0.10 \pm 0.02$ \\
\hline \multirow{5}{*}{ JS-07 } & $0-20$ & $13.91 \pm 0.16$ & $140.07 \pm 17.11$ & $0.10 \pm 0.01$ \\
\hline & $20-40$ & $14.98 \pm 0.30$ & $176.35 \pm 31.56$ & $0.09 \pm 0.02$ \\
\hline & $40-60$ & $17.11 \pm 0.51$ & $175.40 \pm 11.73$ & $0.10 \pm 0.00$ \\
\hline & $60-80$ & $16.53 \pm 0.34$ & $274.56 \pm 25.46$ & $0.06 \pm 0.01$ \\
\hline & $80-100$ & $14.34 \pm 0.39$ & $229.53 \pm 14.13$ & $0.06 \pm 0.00$ \\
\hline
\end{tabular}


at top layers. The soils contain montmorillonite, vermiculite, kaolinite and muscovite as the main mineral phases. Smectite and vermiculite exhibited swelling capabilities, and vermiculite was mostly found in soils of subtropical and temperate climates. Montmorillonite is often reported to intermix with muscovite, chlorite, illite and kaolinite. In all profiles, fine clay $(<0.002 \mathrm{~mm})$ samples had dominant mineral phase of montmorillonite, vermiculite, and muscovite, except for profiles $\mathrm{HN}-10$ and JS-07 which also contained nentronite (Fig. 3). Smectites are considered most important in the development of soils in temperate regions; seasonally wet and dry climates are responsible for

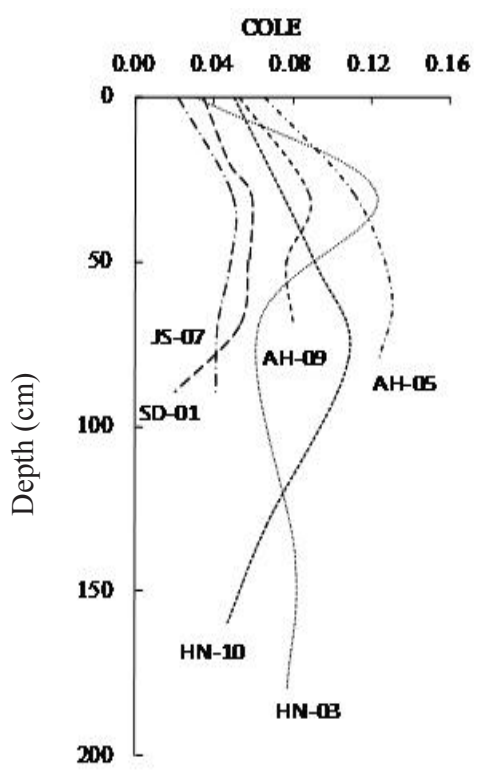

Fig. 2. Variation in COLE values of soils (AH-05, AH-09, SD-01, HN-03, HN-10 and JS-07) along their depth. swelling and shrinkage properties of soils. Smectite with vermiculite have a high cation exchange capacity and a high affinity for exchanging $\mathrm{K}^{+}, \mathrm{Ca}^{2+}$, and $\mathrm{Mg}^{2+} . \mathrm{K}, \mathrm{Mg}$ and glycerol saturation along with heating were applied to distinguish swelling and non-swelling 2:1 clay minerals.

Figure 4 shows XRD results of soil profiles which were subjected to different treatments of ethylene glycerol, $\mathrm{Mg}$ and $\mathrm{K}$ saturation in order to illustrate the complexity of verities of expandable layer sequences in the samples. Smectite (montmorillonite and nentronite) expands on ethylene glycerol and $\mathrm{Mg}$ treatments in all samples. Montmorillonite is known as $\mathrm{Al}$ rich, dioctahydral smectite formed from primary octahyderal substitutions of $\mathrm{Mg}$. Figure $4 \mathrm{a}, \mathrm{b}$ show that smectite (montmorillonite) and vermiculite phases are dominant after glycolation and $\mathrm{Mg}$ saturation, but with $\mathrm{K}$ and subsequent temperature (350 and $550^{\circ} \mathrm{C}$ ) application these phases converted to muscovite. Vermiculites are generally formed by alteration of miceous minerals (chlorite to trioctahyderal vermiculite, muscovite to dioctahyderal vermiculite) and mostly $\mathrm{Mg}$ saturated vermiculite collapses on heating, ie at $550^{\circ} \mathrm{C}$. Muscovite (non-swelling) is common mica composed of phyllosilicate mineral of $\mathrm{Al}$ and $\mathrm{K}$.

Figure 4c, d, e (profiles SD-01,HN-03 and HN-10) show illite and vermiculite phase on addition of $\mathrm{Mg}$ and ethylene glycerol, which also suggested that these soils have mixed layer of clays. The illite phases disappear by $\mathrm{K}$ addition and temperature treatments. Figure $4 \mathrm{c}$ shows soil samples having vermiculite and smectite as major phases and with addition of $\mathrm{K}$ these phases converted into illite and later to muscovite with application of temperature. Figure $4 \mathrm{~d}$ exhibits smectite, vermiculite and kaolinite phases in air dried samples, while it converted to vermiculite with glycolation and $\mathrm{Mg}$ addition and later to muscovite with addition of $\mathrm{K}$ and temperature. Similar results were also found for HN-10

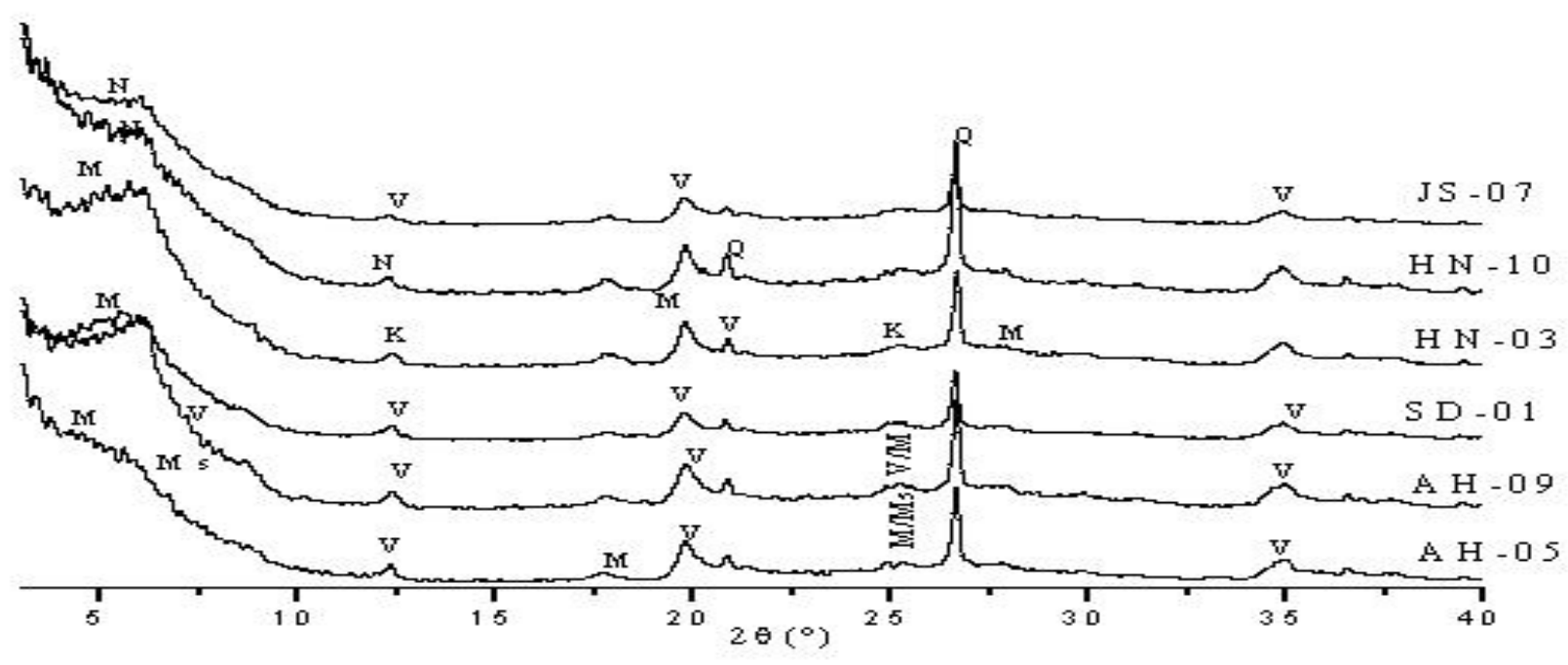

Fig. 3. XRD analysis of air dried samples of all soils at top layer $(\mathrm{M}$ - montmorillonite, $\mathrm{K}$ - kaolinite, Ms - muscovite, $\mathrm{V}$ - vermiculite, $\mathrm{Q}$ - quartz, M/Ms - montmorillonite/muscovite, $\mathrm{N}$ - nontronite). 
a

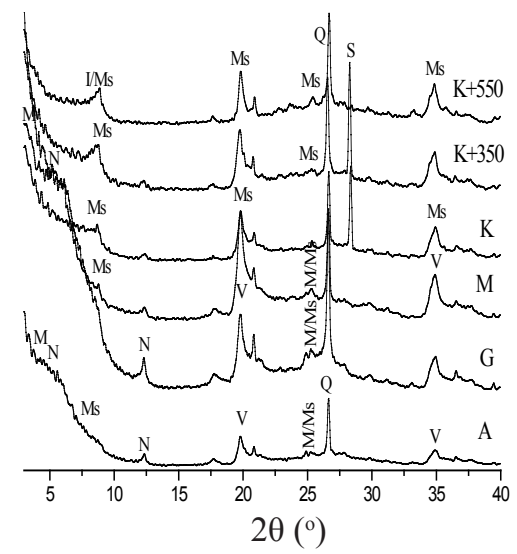

c

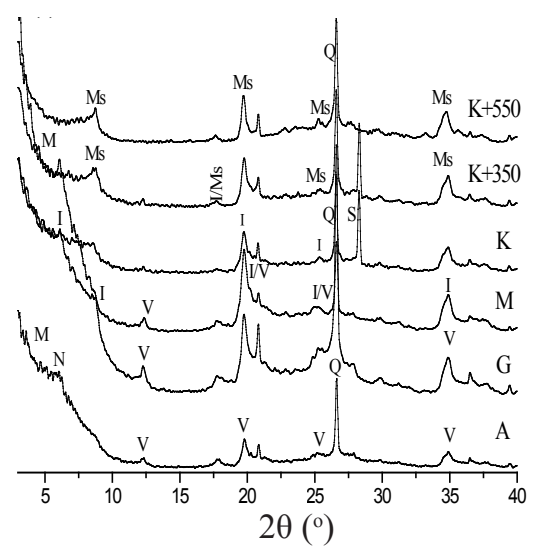

e

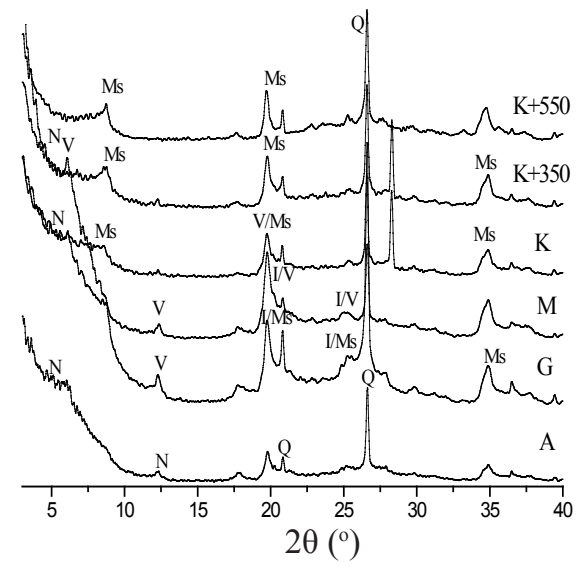

$\mathrm{b}$

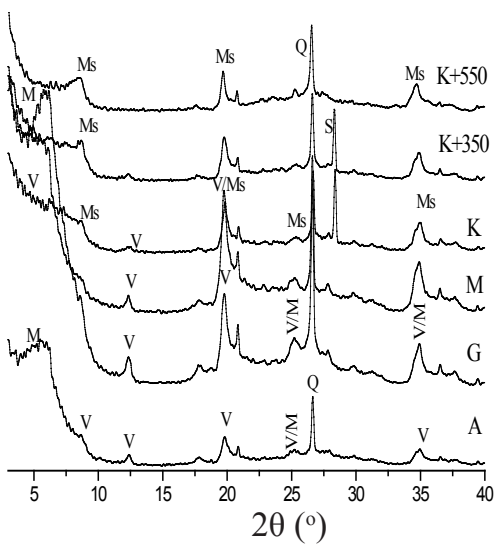

d

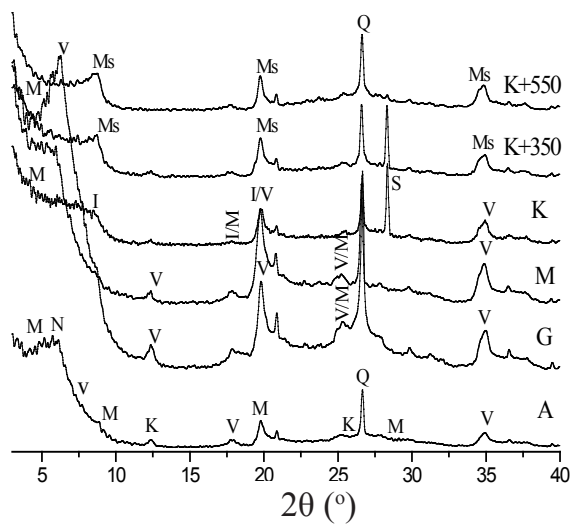

f

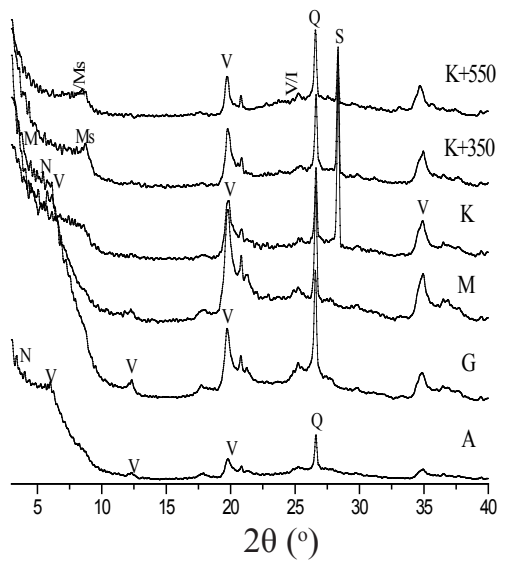

Fig. 4. XRD of soils (a) AH-05 (b) AH-09 (c) SD-01 (d) HN-03 (e) HN-10 (f) JS-07 with A - air dried, G - Ethylene glycerol, M $\mathrm{MgCl}_{2}, \mathrm{~K}-\mathrm{KCl}, \mathrm{K}+350-\mathrm{KCl}+350{ }^{\circ} \mathrm{C}$ and $\mathrm{K}+550-\mathrm{KCl}+550^{\circ} \mathrm{C}$ treatments. Explanations as in Fig. 3. 
and JS-07 profiles (Fig. 4e, f), where vermiculite and illite phases changed to muscovite with addition of $\mathrm{K}$ and temperature, while smectite phase expanded with glycolation and $\mathrm{Mg}$ addition. Addition of $\mathrm{Mg}$ and $\mathrm{K}$ in clay mineral predicted the behaviour of smectite and vermiculite layers of variable charge. As confirmed from Fig. 4, the addition of $\mathrm{Mg}$ clearly distinguished the vermiculites from smectites. Vermiculites were distinguished from smectite by having $1.45 \mathrm{~nm}$ peaks compared to smectites at $1.77 \mathrm{~nm}$. Addition of $\mathrm{K}$ and temperature treatments resulted in the loss of expandable layers, while expansion of fine clay $(<0.002 \mathrm{~mm}$ ) with $\mathrm{Mg}$ saturation and glycolation (ethylene glycerol) confirmed the presence of smectite and vermiculite. The abovementioned results revealed that high COLE values were found along depths for all the soil profiles, except depths $>80$ and $>150 \mathrm{~cm}$ for profiles SD-07 and $\mathrm{HN}-10$, respectively. Tensile strength of profiles AH-05, AH-09, SD-01, HN-03 and HN-10 increased with increasing depth. Shear strength showed high values of cohesion for profiles AH-05, AH-09, HN-03 and HN-10 along the depth whereas angle of friction values decreased. Cohesion values for profile SD-01 gradually decreased from top layer to bottom layer while no marked differences were observed for shear strength in profile JS-07 with depth. Cracking area increasedinprofilesAH-05,AH-09, SD-01 and JS-07 whereas crack length increased in profiles $\mathrm{HN}-03$ and $\mathrm{HN}-10$. XRD analysis showed that the mineralogy of the profiles was composed of smectite and vermiculite phases, and smectite was dominant in the fine clay fraction along the depth.

PCA was applied to all the soil data (Fig. 5). The principal component which had eigenvalue higher than 1 was extracted and two components were obtained. The first component accounted for $70.62 \%$ of variances for all of

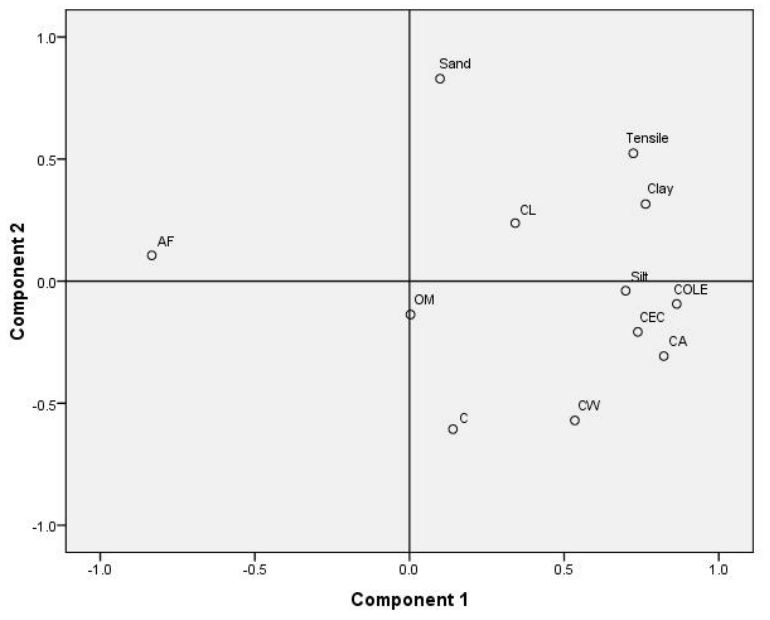

Fig. 5. Principal component analysis of soil parameters of all studied soils. Clay - clay contents $(<0.002 \mathrm{~mm})$, sand, silt, CEC, Tensile - tensile strength, OM - organic matter, $\mathrm{C}$ - cohesion, $\mathrm{AF}$ - angle of friction $(\varphi), \mathrm{CA}$ - crack area, $\mathrm{CL}$ - crack length, $\mathrm{CW}$ - crack width. the data. The first component revealed that at component 1 COLE, CEC, tensile strength, clay, silt and crack area were positively correlated with each other, while negatively correlated with the angle of friction $(\varphi)$.

\section{DISCUSSION}

Physical properties of soils are important indicators for agricultural production. Our results demonstrated that the unproductive soils of Northern China have high amounts of clay and smectite. The higher values of mechanical and physical properties like COLE, tensile and shear strength were observed in the studied profiles, while cracking parameters indicated that these soils are subject to swelling and shrinkage. The results suggest that the amount of clay and clay mineralogy are responsible for the poor physical properties of these soils. PCA analysis (Fig. 5) indicated that tensile properties of soil profiles were positively correlated with the amount of fine clay. The positive correlation of tensile strength with CEC and clay content suggested that this property solely depends on the clay contents in the soils (Greene et al., 2002). Similar to our findings, Imhoff et al. (2002) reported a positive correlation of tensile strength with clay and silt contents and organic matter. Increase in the values of tensile strength with depth was probably due to increase in clay content, low organic matter, and less microbial activity (Abid and Lal, 2009; Blanco-Canqui and Lal, 2007). We found high values of tensile strength for profiles $\mathrm{AH}-05, \mathrm{AH}-09, \mathrm{HN}-03$ and HN-10 with varying depth. The results suggest that the high values in the tensile strength properties may be due to the amount of clay and its mineralogy with the depth. Similarly it was found previously that an increase in the tensile strength was more pronounced in clayey soil than silty loam soil (Zhang et al., 1997).

The shear strength, cohesion and angle of friction exhibited irregular trends at different depths of different profiles (Table 2). Several factors could be responsible for the irregular trends in the shear strength along the depths, such as clay content, mineralogy, cohesive forces, soil granulometry, organic matter and water contents (Wilson et al., 2013). Bhattarai et al. (2007) also found irregular trends in the cohesion and angle of friction with depth for different profiles. The results suggested that the irregular trends in shear strength are probably due to variation in the clay contents along the depth as well as to the mineralogy of soil (Tiwari and Ajmera, 2011). PCA analysis also showed a positive correlation between the cohesion and CEC and clay content, whereas the angle of friction had a negative correlation with CEC and clay contents (Fig. 5). In our results, cohesion of soil profiles increases with increase in clay content, however the angle of friction decreases in a similar pattern. The mineralogy of the investigated soils was mostly composed of smectite (montmorillonite), which had a negative effect on the angle of friction, as also found in other studies (Al-Shayea, 2001; Stark and Eid, 1994; 
Tiwari and Marui, 2005). The positive correlation between clay contents and cohesion in the soil profiles suggested that it might be due to clay minerals and arrangement of the particles.

The low yield soils of Northern China are composed of large amount of expansive clay minerals which absorb high quantities of water and increase their volume. Upon drying, these clay minerals shrink and cause cracking in soil and made the soil difficult for management. The soil samples showed variation in their cracking properties with relation to clay contents and clay types. Profiles AH-05, AH-09, SD-01 and JS-07 showed high values for crack area with increasing depth, whereas the values of crack area decreased in profiles $\mathrm{HN}-03$ and $\mathrm{HN}-10$. The cracks length increases along depth in profiles $\mathrm{HN}-03$ and $\mathrm{HN}-10$ due to variation in their clay contents. The results suggested that the soil profiles might be subject to cracking upon drying. The phenomenon of cracking in soil depends on the amount and type of clay minerals (Moormann, 1978). Smectite induces vast changes in the shrinkage properties of soils due to the small pore sizes and porosity of smectites (Boivin et al., 2004). Mostly the clay minerals composed of high amount of montmorillinite have a high shrink-swell potential. Our XRD results showed that all of the profiles have a high amount of smectites (montmorillinite) and, moreover, the PCA analysis (Fig. 5) revealed that cracking parameters were positively correlated with CEC and clay $\%$. These results suggested that cracking parameters in our samples were dependent on clay mineralogy and on the amount of clay. Shrinkage and swelling potential of soil is usually measured through shrinkage characteristics curves, COLE, and from the correlation with clay contents. Cracking parameters in our samples were correlated with clay contents, CEC and COLE (Fig. 5). Change in shrinkswell potential with water content in soil was related to COLE, and the variation in vertical shrinkage and swelling could be explained by variation in COLE (Crescimanno and Provenzano, 1999; Dinka et al., 2012).

Variation in COLE values in sub-layers of all profiles was probably due to variation in clay \% (Fig. 2). The results indicated that profiles AH-05, AH-09, HN-03 and HN-10 showed high values of COLE in the sub-layers with high percentage of clay content and CEC. High COLE values are also found in other studies (Moustakas, 1990) and COLE value greater than $0.03 \mathrm{~cm} \mathrm{~cm}^{-1}$ suggests having a high amount of montmorillonite (Grossman et al., 1968). XRD analysis (Figs 3, 4) showed that all profiles of the soils of Northern China are composed of smectite (montmorillonite) and vermiculite, so we can say that the mineralogy of the soils was mainly responsible for the high values of COLE in our samples. A positive correlation was observed between COLE, CEC and clay content (Fig. 5), which further strengthens the assumption that smectite mainly controlled the shrink-swell properties of the soils, along with high clay contents. Moustakas (2012) found similar results for vertisol soils, where the author found a positive correlation between COLE, total clay content and CEC. The high values of CEC $\left(\geq 50 \mathrm{cmol} \mathrm{kg}^{-1}\right)$ showed the presence of a considerable amount of smectitic clay (Greene et al., 2002), and the high amount of smectite in the soil controlled the shrink and swelling phenomenon. In our results, XRD analysis showed that smectite was more abundant in soil profiles with a considerable amount of hydroxy-interlayer (vermiculite). These hydroxy-interlayers are not easily detected with glycolation but are evident with $\mathrm{K}$ saturation and heating at $550^{\circ} \mathrm{C}$, with a broad peak of $10 \mathrm{~nm}(\mathrm{Pal}$ et al., 2012). Figure 4 depicts the conversion of hydroxylinterlayer (vermiculite) to muscovite $(10 \mathrm{~nm})$ on addition of $\mathrm{K}$ and subsequent heat treatment at 350 and $550^{\circ} \mathrm{C}$. The inter-conversion of mica to vermiculite is a result of weathering of $\mathrm{K}$ which was released from trapped position in the mica lattice to form hydrous mica or illite, and to vermiculite with an addition of water and swelling of clay lattice (Biswas and Mukherjee, 2001). The interlayer phases in smectite are not only hydrated but also expansible, depending on the type and concentration of cations in the interlayer and on the amount of water in the soil. Due to the presence of these expansible interlayers, smectite is often referred as swelling clay. On the other hand, vermiculite is somewhat expansible but less so than smectite because of $\mathrm{K}$ ions present in the interlayer hold the layer together. Hence the swelling and shrinkage behaviour is controlled by the presence of smectite and vermiculite, as it is clear from the XRD results of six soil profiles of Northern China. From the above discussion it is evident that many physical properties of the soils of Northern China are controlled by the CEC, clay \%, COLE and smectite. The correlation of these parameters with tensile strength and cracking characteristics might be mainly responsible for the low yields in Northern China. The above studied soil profiles are major grain (wheat, maize and peanuts) as well as vegetables and cotton producing areas of Northern China plains. The high values of tensile strength of these soils reflect the extent of soil stiffness which is an important factor controlling physical properties of soils by offering resistance in the tillage operations and plant root growth. Shijiang black soil was reported to be a stiff, thin, barren and low yield soil affected by flood and drought spells (Liu et al., 2011). Similarly, the development of large cracks (both vertical and horizontal) in these soils is another character that makes them difficult for crop production ie depletion of moisture from deep layers, breakage of young plants roots, exposure of root to external harsh environment, deterioration of soil porosity and blockage of ground water supply to plough layers (Huang et al., 1997). 


\section{CONCLUSIONS}

1. Unproductive soils of Northern China are characterized by high amount of fine clay $(<0.002 \mathrm{~mm})$, rich in smectite (montmorillonite) mineral with its high cation exchange capacity values. This mineral is mainly responsible for physical functions of the soil profiles.

2. Soil profiles were subject to cracking upon drying. They showed variations in their cracking properties according to clay contents and clay type.

3. Principle component analysis showed that tensile strength, cohesion, cracking characteristics, clay content, cation exchange capacity and coefficient of linear extensibility were positively correlated with each other, whereas negatively correlated with angle of friction, indicating that these properties were dependent on clay content and smectite content. These correlations might be mainly responsible for low productivity (low yields) of the soils in Northern China.

\section{REFERENCES}

Abid M. and Lal R., 2009. Tillage and drainage impact on soil quality: II. Tensile strength of aggregates,moisture retention and water infiltration. Soil Till. Res., 103, 364-372.

Al-Shayea N.A., 2001. The combined effect of clay and moisture content on the behavior of remolded unsaturated soils. Eng. Geo., 62, 319-342.

Bao S.D., 2000. Soil and Agricultural Analysis (In Chinese). China Agricultural Press, Beijing, China.

Bandyopadhyay K., Mohanty M., Painuli D., Misra A., Hati K., Mandal K., Ghosh P., Chaudhary R., and Acharya C., 2003. Influence of tillage practices and nutrient management on crack parameters in a Vertisol of central India. Soil Till. Res., 71, 133-142.

Bhattarai P., Marui H., Tiwari B., Watanabe N., and Tuladhar G., 2007. Depth-wise variation of physical and mechanical properties of mudstone in relation to weathering. J. Jpn. Ls. Soc., 44, 79-89.

Biswas T.D. and Mukherjee S., 2001. Textbook of Soil Science. Tata McGraw-Hill, New Delhi, India.

Blanco-Canqui H. and Lal R., 2007. Soil structure and organic carbon relationships following 10 years of wheat straw management in no-till. Soil Till. Res., 95, 240-254.

Boivin P., Garnier P., and Tessier D., 2004. Relationship between clay content, clay type, and shrinkage properties of soil samples. Soil Sci. Soc. Am. J., 68, 1145-1153.

Crescimanno G. and Provenzano G., 1999. Soil shrinkage characteristic curve in clay soils: Measurement and prediction. Soil Sci. Soc. Am. J., 63, 25-32.

Dadfar H., Allaire S.E., De Jong R., van Bochove E., Denault J.T., Theriault G., and Dechmi F., 2010. Development of a method for estimating the likelihood of crack flow in Canadian agricultural soils at the landscape scale. Can. J. Soil Sci., 90, 129-149.

Dinka T.M., Morgan C.L., McInnes K.J., Kishné A.S., and Daren H.R., 2012. Shrink-swell behavior of soil across a Vertisol. Catena, J. Hyd., 476, 352-359.

Donghong X., Dan Y., Jiajia L., Zheng'an S., Yifan D., and Juan Z., 2013. Influence factors of morphological development of soil cracks in degraded slopes in Yuanmou dry-hot valley region (in Chinese). Tran. Chi. Soc. Agr. Eng., 29, 102-108.

Greene R.S., Eggleton R.A., and Rengasamy P., 2002. Relationships between clay mineralogy and the hardsetting properties of soils in the Carnarvon horticultural district of Western Australia. Appl. Clay Sci., 20, 211-223.

Grossman R., Brasher B., Franzmeier D., and Walker J., 1968. Linear extensibility as calculated from natural-clod bulk density measurements. Soil Sci. Soc. Am. J., 32, 570-573.

Huang D.M., Zhu P.li., Li Q.K., Yu X.H., and Yu J., 1997. Hydrophysical characteristics of Vertisol in low land areas of Jiangsu province (in Chinese). Jiangsu J. of Agr. Sci., 13, 44-50.

Imhoff S., da Silva A.P., and Dexter A., 2002. Factors contributing to the tensile strength and friability of Oxisols. Soil Sci. Soc. Am. J., 66, 1656-1661.

Li D., Zhang G., and Gong Z., 2011. On Taxonomy of Shajiang Black Soils in China (in Chinese). Soils, 43, 623-629.

Liangwu L., 1991. Formation and evolution of Vertisols in Huaibei Plain. Pedosphere 1, 3-15.

Liu S.F., Qin S.Y., Ge C.B., and Zhang Y.D., 2011. Study on wheat production status of Shajiang black soil (in Chinese). Mod. Agr. Sci. and Tech., 22, 292-302.

Min Z., Liangwu L., and Zitong G., 1993. Age and some genetic characteristics of Vertisols in China. Pedosphere, 3, 247-256.

Moormann F.R., 1978. Rice: Soil, Water, Land. Int. Rice Res. Inst., Los Banos, Laguna, Phillipines.

Moustakas N., 1990. Relations between morphological and physicochemical properties of Vertisols in Greece. Ph.D. Thesis, Agricultural University of Athens, Greece.

Moustakas N., 2012. A study of Vertisol genesis in North Eastern Greece. Catena, 92, 208-215.

Pal D., Wani S., and Sahrawat K., 2012. Vertisols of tropical Indian environments: Pedology and edaphology. Geoderma, 189, 28-49.

Schafer W.M. and Singer M.J., 1976. A new method of measuring shrink-swell potential using soil pastes. Soil Sci. Soc. Am. J., 40, 805-806.

Stark T.D. and Eid H.T., 1994. Drained residual strength of cohesive soils. J. Geo. Eng., 120, 856-871.

Tiwari B. and Ajmera B., 2011. Consolidation and swelling behavior of major clay minerals and their mixtures. Appl. Clay Sci., 54, 264-273.

Tiwari B. and Marui H., 2003. Estimation of residual shear strength for bentonite-kaolin-Toyoura sand mixture. J. Jpn. Ls. Soc., 40, 124-133.

Tiwari B. and Marui H., 2005. A new method for the correlation of residual shear strength of the soil with mineralogical composition. J. Geotech. Geoenviron., 131, 1139-1150.

Wilson M.G., Sasal M.C., and Caviglia O.P., 2013. Critical bulk density for a Mollisol and a Vertisol using least limiting water range: Effect on early wheat growth. Geoderma, 192, 354-361.

Xuelei Z. and Zitong G., 2004. A pedodiversity pattern: taxonomically established soil orders in China. J. Geogr. Sci., 14, 52-56.

Zhang H., Hartge K., and Ringe H., 1997. Effectiveness of organic matter incorporation in reducing soil compactibility. Soil Sci. Soc. Am. J., 61, 239-245. 